\title{
Estimation of canopy drying time after rainfall using sap flow measurements in an emergent tree in a lowland mixed-dipterocarp forest in Sarawak, Malaysia
}

\author{
Tomonori Kume, ${ }^{1 *}$ Koichiro Kuraji, ${ }^{2}$ Natsuko Yoshifuji, ${ }^{1}$ Toshiyuki Morooka, ${ }^{1}$ \\ Shinji Sawano, ${ }^{1}$ Lucy Chong $^{3}$ and Masakazu Suzuki ${ }^{1}$ \\ ${ }^{1}$ Graduate School of Agricultural and Life Sciences, University of Tokyo, 1-1-1 Yayoi, Bunkyo-ku, Tokyo 113-8657, Japan \\ ${ }^{2}$ University Forest in Aichi, Graduate School of Agricultural and Life Sciences, University of Tokyo, 11-44 Goizuka-cho, Seto, Aichi \\ 489-0031, Japan \\ ${ }^{3}$ Forest Research Center, 93250 Kuching, Sarawak, Malaysia
}

\begin{abstract}
:
This study emphasizes the importance of canopy drying time (CDT) after rainfall in a lowland tropical rain forest. In this study, we estimate CDT using sap flow velocities measured by a heat-pulse method in an emergent tree in a lowland mixed-dipterocarp forest. Estimated CDT (ECDT) for each rain event has been defined as the time from rainfall cessation to the specific time derived from the difference between diurnal courses of sap flow velocities on a rainy day versus bright days. ECDT could be derived for 22 rain events that were grouped into two types, depending on whether rainfall ceased before or after noon. The ECDTs were distributed more widely and with greater values when rainfall ceased before noon (Type 1) than after noon (Type 2). The ECDTs of both Type 1 and Type 2 decreased with increases in net radiation (Rn) and vapour pressure deficit (VPD) after rainfall. This result shows that ECDT is determined mainly by post-rainfall evaporation rates. The sap flow velocity as a detector of canopy wetness worked out well because of the specific rainfall characteristics at this site. The practical limitations of the method using sap flow velocities are discussed in relation to rainfall characteristics and time lags between transpirations and sap flow velocities. Copyright (C) 2005 John Wiley \& Sons, Ltd.
\end{abstract}

KEY WORDS heat-pulse method; sap flow velocity; rainfall; canopy drying time (CDT); lowland mixed-dipterocarp forest

\section{INTRODUCTION}

An estimated $15 \%$ of forests in humid tropical Asia have been converted to other land uses within the last 15 years (Houghton and Hackler, 1999). Such regional land-use changes can lead to a decrease in evapotranspiration from the ground surface, a hydrological change that may occasionally reduce regional rainfall (Kanae et al., 2001). To assess the effects of deforestation on a regional environment, it is important to understand water vapour-exchange processes between forest and atmosphere.

The water vapour-exchange processes, which consist mainly of wet canopy evaporation and dry canopy transpiration, are quite different depending on whether the canopy is wet or dry. Canopy drying time (CDT) is the period needed to dry out canopy exposed to rainfall; wet canopy gradually shifts to dry canopy. In a lowland tropical rain forest, short rain events occur more frequently than in other climatic regions (Kuraji, 1996), which leads to more frequent occurrences of CDT than in other climatic regions. In lowland tropical rain forests, understanding the variations of CDT will be one of the keys to estimating evapotranspiration over the long term.

\footnotetext{
* Correspondence to: Tomonori Kume, Graduate School of Agricultural and Life Sciences, University of Tokyo, 1-1-1 Yayoi, Bunkyo-ku, Tokyo 113-8657 Japan. E-mail: kumett@fr.a.u-tokyo.ac.jp 
A numerical model for estimating evapotranspiration has been formulated using the different functions of wet and dry canopy (Rutter et al., 1975; Watanabe and Mizutani, 1996; Bigelow, 2001; Bosveld and Bouten, 2003; Takanashi et al., 2003; Tanaka et al., 2003). To validate the models, transpirations or latent heat fluxes (Watanabe and Mizutani, 1996; Bosveld and Bouten, 2003; Takanashi et al., 2003; Tanaka et al., 2003), and measurements of throughfall and stem flow (Bigelow, 2001; Tanaka et al., 2003) have been used. A recent study also uses CDT to validate the model (Takanashi et al., 2003). Not including CDT as part of the data for validation may cause a serious error in estimating evapotranspiration, especially in lowland tropical rain forests, where short rain events occur frequently throughout the year. However, there is little understanding of CDT characteristics in lowland tropical rain forests.

When examining CDT, canopy wetness should be measured in situ. To this aim, several methods of monitoring plant wetness have been investigated, including a wetness sensor developed by plant pathologists (Wei et al., 1995; Giesler et al., 1996; Miranda et al., 2000). Since the wetness sensor measures leaf-scale wetness ( $3 \mathrm{~cm} \times 3 \mathrm{~cm}$; Miranda et al., 2000), a series of wetness sensors must be placed at different heights within a canopy, and then the method applied to the entire canopy. Remote-sensing techniques, such as those based on gamma-rays (Calder and Wright, 1986) and microwaves (Bouten et al., 1996), allow continuous monitoring of the canopy through complex calibrations. Although they can measure canopy-scale wetness (a sensor and receiver were each installed on separate towers standing $15 \mathrm{~m}$ apart; Bouten et al., 1996), they are expensive to implement, and some platforms are required to install the series of wetness sensors and remote sensors within a canopy. Lowland tropical rain forests are characterized by tall emergent trees, which are sometimes taller than $70 \mathrm{~m}$ in Southeast Asia (Kira, 1978). This makes it difficult to apply these techniques in the lowland tropical rain forests, and may be one of the reasons why knowledge of CDT characteristics is lacking for this type of ecology.

Rainfall reduces transpiration, because evaporative energy is consumed for evaporating the water on the canopy (Rutter et al., 1975; Bosveld and Bouten, 2003). It is still possible to derive valuable information on canopy wetness when reduction of transpiration by rainfall occurs by measuring the sap flow velocity to estimate tree transpiration. This can be conducted easily and interfaced readily through data loggers for long-term observations (e.g. Swanson, 1994; Wullschleger et al., 1998).

In this study, we propose that CDT can be estimated using sap flow velocities measured by a heat-pulse method. We discuss the reasons for using this method and its practical limitations. Although this paper examines estimated CDT characteristics in an emergent tree in a lowland mixed-dipterocarp forest, we are not attempting to validate the results obtained using sap flow velocity by independent canopy wetness observations. Even so, we believe this paper has novelty, because, to our knowledge, there are no other studies dealing with a wet canopy drying process in lowland tropical rainforests using sap flow measurements.

\section{METHODS}

Site

The study site is located in Lambir Hills National Park, Sarawak, Malaysia $\left(4^{\circ} 20^{\prime} \mathrm{N}, 113^{\circ} 50^{\prime} \mathrm{E}\right)$, situated about $30 \mathrm{~km}$ southwest of Miri, the capital of the Fourth Division, Sarawak, and about $12 \mathrm{~km}$ from the nearest coast (Figure 1). The mean annual temperature at Miri Airport, situated $24 \mathrm{~km}$ northeast of the park, is about $27^{\circ} \mathrm{C}$ with slight seasonal variation. The mean annual rainfall at the airport is about $2700 \mathrm{~mm}$ and is distributed evenly throughout the year.

The park has an area of 6949 ha, $85 \%$ of which is covered by the lowland mixed-dipterocarp forest common to Borneo (Yamakura et al., 1995; Itoh et al., 1997; Condit et al., 2000), with a continuous canopy height of approximately $50 \mathrm{~m}$. The park contains a $49.5 \mathrm{~m}$ tree tower. Kumagai et al. (2001) has reported the total leaf area index of the site $\left(5.1 \mathrm{~m}^{2} \mathrm{~m}^{-2}\right)$ and its vertical profile using the tower. The target tree in this study was an emergent tree, Dipterocarpus pachyphyllus, adjacent to the tower (Figure 2) about $48 \mathrm{~m}$ in height with a diameter at $5 \mathrm{~m}$ from the ground of $136 \cdot 1 \mathrm{~cm}$ (Hiromi et al., 1999). 


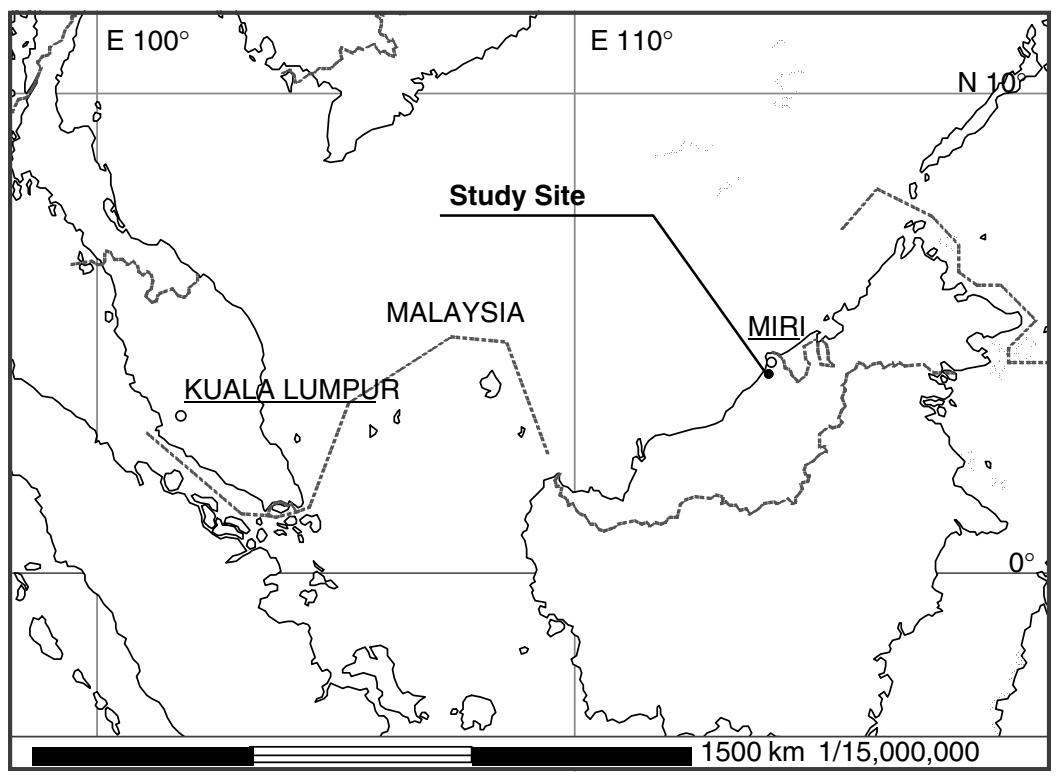

Figure 1. Study site, situated about $30 \mathrm{~km}$ southwest of Miri in Sarawak, Malaysia



Figure 2. Schematic representation of the tree tower, equipment, and the target tree 


\section{Sap flow determined by the heat-pulse method}

Sap flow velocities were measured continuously from June 2001 through to March 2002 using the thermoelectric heat-pulse method (Closs, 1958; Marshall, 1958). The instrumentation consisted of three sets of a sensor (HP-1, Hayasi Denko Co., Tokyo, Japan) containing a heater probe and two thermistor probes $(2.0 \mathrm{~mm}$ in diameter, $50 \mathrm{~mm}$ in length). The heater probe was inserted radially into the target tree branch about $35 \mathrm{~m}$ above ground level. Two thermistor probes were vertically aligned asymmetrically around the heater probe. The upper probe and lower probe were spaced $10 \mathrm{~mm}$ and $7 \mathrm{~mm}$ respectively from the heater probe. The three sensors were installed in holes drilled with a gauge guide into the outer xylem to a depth of $20 \mathrm{~mm}$, as shown in Figure 2. A heat-pulse tracer was released for a duration of $1.5 \mathrm{~s}$ every $20 \mathrm{~min}$, and the temperature difference between thermistor probes was measured every $0.25 \mathrm{~s}$. The time delay for the same temperature increase to occur at both thermistor probes was recorded with a solid-state memory module (CR10X, Campbell Scientific Inc., Logan, UT, USA). Heat pulse velocities were calculated by Closs's (1958) method as follows:

$$
\mathrm{HPV}=\frac{\mathrm{OA}-\mathrm{OB}}{2 t_{0}} \times 3600
$$

where HPV $\left(\mathrm{cm} \mathrm{h}^{-1}\right)$ is the heat pulse velocity, OA $(\mathrm{cm})$ is the distance from the heater probe to the upper probe, $\mathrm{OB}(\mathrm{cm})$ is the distance from the heater probe to the lower probe, and $t_{0}(\mathrm{~s})$ is the time delay for the same temperature increase to occur at both thermistor probes. In this instrumentation, a minimum measurable HPV is $0.63 \mathrm{~cm} \mathrm{~h}^{-1}$, as a maximum $t_{0}$ was set for $860 \mathrm{~s}$. Kominami and Suzuki (1993) have validated the measurement accuracy of this type of system by comparing it with stem cutting methods.

To account for the influence of sap flow interruption around an implanted sensor, the HPV calculated by Equation (1) was adjusted to sap flow velocities using Swanson's method (Swanson and Whitfield, 1981; Kominami and Suzuki, 1993). Yoshifuji et al. (2001) reported that HPV values decreased gradually in longterm, continuous measurements. To eliminate the influence of the gradual decrease caused by long-term observation, some adjustments should be made in addition to Swanson's method.

Previous studies have indicated that tree sap flow tends to plateau under conditions of high solar radiation and vapour pressure deficit (VPD; Hogg and Hurdle, 1997; Meinzer et al., 1993; Granier et al., 1996), which suggests that sap flow velocities will be nearly the same under conditions of high solar radiation and VPD. Therefore, adjustments for the decreasing of long-term sap flow velocities can be made as follows. (1) A linear regression equation can be derived between the date and the observed daily sap flow velocities on bright days. From this equation, the daily sap flow velocity expected on a bright day can be calculated for all day. (2) All observed daily sap flow velocities can be adjusted using the ratio of the daily sap flow velocity expected on a bright day to the intercept of that equation. This intercept would be the sap flow velocity expected on a bright day without the influence of a gradual decline. (3) The adjusted daily sap flow velocities are then adjusted for each time in proportion to what was observed every $20 \mathrm{~min}$ each day.

\section{Definition of estimated CDT}

Transpiration is reduced during the period of canopy wetting, because evaporative energy is consumed for evaporating the water on the leaves. When evapotranspiration from wet canopy is calculated using a numerical model, it is assumed that the proportion $S / S_{\max }$ (i.e. the ratio of the actual water stored on the leaves to the canopy saturation value) of the total leaf area is covered by intercepted water, whereas the rest of the area is open to transpiration (e.g. Rutter et al., 1975; Watanabe and Mizutani, 1996; Bosveld and Bouten, 2003). In addition, physiological responses for rain are also reported. The stomata of leaves close momentarily when exposed to rain (Monzi, 1937; Ishibashi and Terashima, 1995), and the water droplets block the leaves' stomata obstructing gas exchange (Kimura and Tanakamaru, 1982).

A canopy dries gradually after rainfall, starting from the top (Watanabe and Mizutani, 1996; Takanashi et al., 2003). As transpiration starts on the dry portion of the leaves, sap flow can be measured before the lower part of the canopy has dried. Takanashi et al. (2003) measured the sap flow velocities in the basal stem 
while measuring the leaf wetness using wetness sensors placed at different heights within the canopy. They showed that sap flow velocity after rainfall peaked at around the time when the lower canopy had completely dried in the afternoon. This suggests that sap flow velocity can be used as an integrator of leaf wetness throughout the canopy of an entire tree.

Generally, factors determining sap flow are solar radiation and VPD (Meinzer et al., 1993; Becker, 1996; Granier et al., 1996; Hogg and Hurdle, 1997; Cienciala et al. 2000; O’Brien et al., 2004), temperature (Lopushinsky, 1986), soil moisture (Kuwada et al., 2002; Lagergren and Lindroth, 2002; Martinez-Vilalta et al., 2003), and canopy wetness. Around this study area, seasonal variations of temperature and solar elevation are small, and the rainfall is distributed evenly throughout the year. This means that sap flow velocity measured at the same time on bright days can have almost the same value throughout the year. When sap flow velocity after rainfall is lower than sap flow velocity expected on a bright day, the decrease is caused by low solar radiation due to cloud cover, low VPD and canopy wetness. Thus, it might be possible to derive an indication of canopy wetness by comparing the measured sap flow velocity and the sap flow velocity modelled on the basis of solar radiation and VPD. However, the model of sap flow velocities is just being developed (O'Brien et al., 2004), and is too complex for our purpose. Instead of the modelled sap flow, we use the sap flow velocity averaged over 20 bright days. When sap flow velocity after rainfall equals the value of the average sap flow velocity over 20 bright days, we consider that the effect of leaf wetness on transpiration is removed and that the canopy is completely dry.

Figure 3 shows the diurnal courses of the sap flow velocity averaged over 20 bright days with standard deviation and the sap flow velocity for a rainy day, as well as during the actual rainfall. In this study, estimated CDT (ECDT) has been defined as follows:

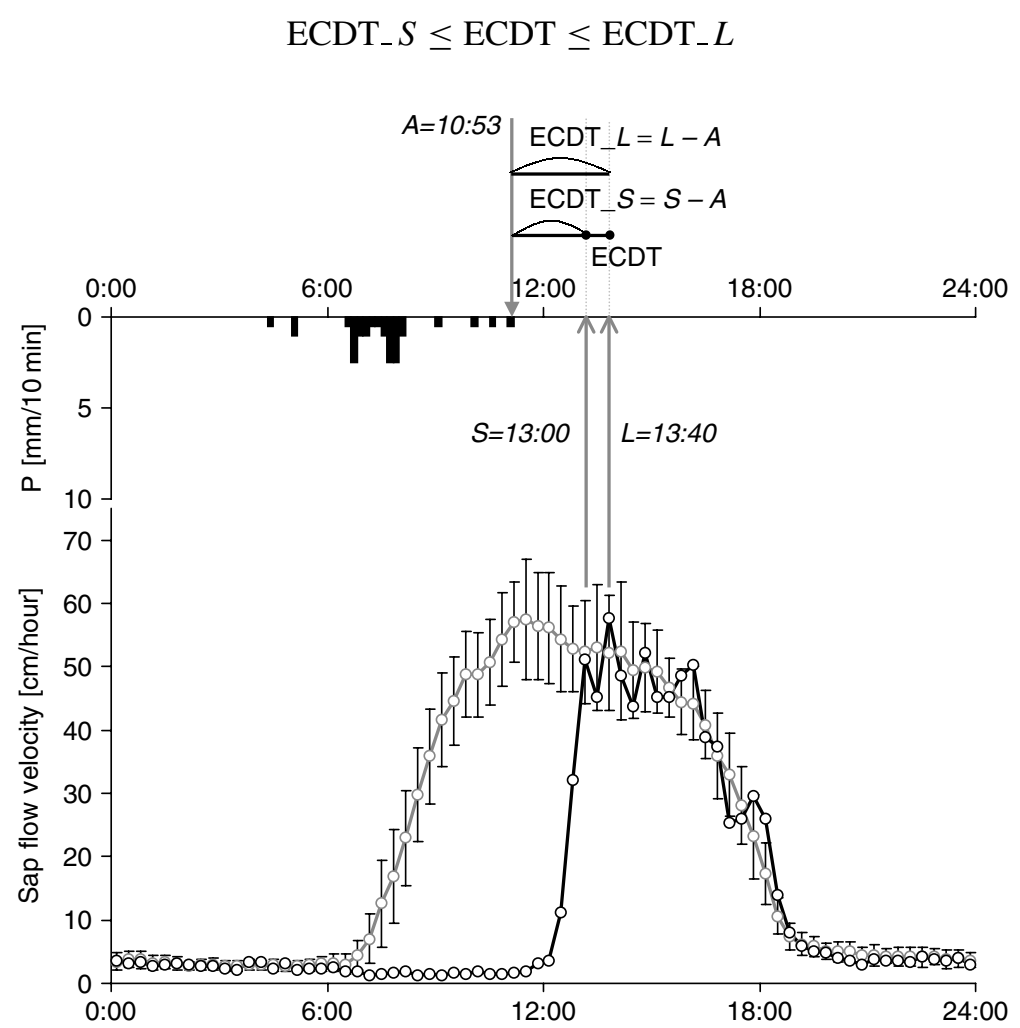

Figure 3. Definition of estimated canopy drying time (ECDT): (a) rainfall $P$; (b) diurnal courses of sap flow velocity during a rainy day (black line) and the average over 20 bright days (grey line). Vertical bars indicate the standard deviation. ECDT_ $S, \mathrm{ECDT}_{-} L, A, S, L$ are defined in the text 
where ECDT $S$ is defined as the period from $A$ to $S$ and ECDT $_{-} L$ is defined as the period from $A$ to $L ; A$ is the time when rain ceased, $S$ is the time when sap flow velocity after rainfall exceeded the average minus the standard deviation of the sap flow velocity averaged over 20 bright days, and $L$ is the time when sap flow velocity after rainfall exceeded the average sap flow velocity over 20 bright days. In this study, we suppose that the wet canopy dries out completely during the period from $S$ to $L$, and so ECDT has been defined as ranging between ECDT_ $S$ and ECDT_ $L$ at each rain event. If sap flow velocity after a rainfall exceeds the average and the average minus the standard deviation of the sap flow velocity over 20 bright days at one interval, then time $S$ will be equal to time $L$ and ECDT_ $S$ will be equal to ECDT_ $L$.

For example, the total rainfall measured for $401 \mathrm{~min}$ from $04: 12$ to $10: 53$ amounted to $16.5 \mathrm{~mm}$ on 16 June (Figure 3). Sap flow velocities were quite low until around noon. Subsequently, the sap flow velocity increased abruptly and exceeded the average minus the standard deviation of the sap flow velocity over 20 bright days at 13:00 (time $S$ ). After $40 \mathrm{~min}$, sap flow velocity exceeded the average sap flow velocity at $13: 40$ (time $L$ ). In this case, ECDT_ $S$ and ECDT_ $L$ are defined as $127 \mathrm{~min}$ and $167 \mathrm{~min}$ respectively, and ECDT is defined as the range between 127 and $167 \mathrm{~min}$. In this analysis, only the sap flow velocities measured with one of the three sensors were used, since the diurnal courses of measurements from each sensor exhibited a remarkable concordance.

\section{Meteorological measurements}

Equipment was installed at the top of the $49.5 \mathrm{~m}$ tower (Figure 2). Air temperature and relative humidity, measured using a thermohygrograph (HMP45A, Vaisala Co., Helsinki, Finland), were recorded with a data logger (SQ1250, Grant Instruments, Cambridge, UK). Net radiation (Rn) was calculated using downward and upward shortwave radiation and downward and upward longwave radiation measured using solarimeters (MS402, Eko Instruments Co., Tokyo, Japan) and infrared radiometers (MS202F, Eko Instruments Co., Tokyo, Japan) respectively. Data acquisitions were made using solid-state memory modules (CR10X, Campbell Scientific Inc.). Rainfall was measured using a tipping-bucket rain gauge $(20 \mathrm{~cm}$ in diameter and $0.5 \mathrm{~mm}$ in tip resolution; Ohta Keiki Co., Tokyo, Japan) and a data logger (Kadec-PLS, Kona System Co., Sapporo, Japan).

\section{RESULTS AND DISCUSSION}

The following three criteria were used to select target rain events: (1) rainfall ceased in the daytime from $06: 00$ to $17: 00$; (2) the period of no rainfall between each rain event exceeded $2 \mathrm{~h}$; (3) total rainfall for each rain event exceeded a threshold of $1.5 \mathrm{~mm}$. The reasons for the three criteria are that sap flow velocity varies markedly in the daytime, and we wanted to deal with rain events that left the canopy fully wet at the time rainfall ceased.

Research on tropical rain forests has measured canopy water storage capacities of less than about $1.5 \mathrm{~mm}$ (e.g. Lloyd et al., 1988; Jetten, 1996; Dykes, 1997; Schellekens et al., 2000). Thus, a threshold of $1.5 \mathrm{~mm}$ is enough rainwater to wet the canopy fully. To guarantee a completely wet canopy at the time rainfall ceased there is the question of whether or not the canopy is drying during a short no-rain period in a rain event. In our study, we included no-rain periods of $2 \mathrm{~h}$ or less, which is shorter than the no-rain periods in previous reports on tropical rain forests. Most of the periods in previous reports are in the 3-12 h range (e.g. Jackson, 1975; Lloyd et al., 1988; Asdak et al., 1998; Schellekens et al., 2000; Manfroi et al., 2004). Additionally, we made sure that sap flow velocity remained low during our target rain events. This suggests that almost the entire leaf surfaces are wetted during rain events. Therefore, it is likely that any drying during the short no-rain periods rarely affects the wet canopy conditions at the time rain ceases in this study.

Table I shows the rainfall characteristics for 22 rain events satisfying our three criteria. Rainfall duration ranged from 1 to $541 \mathrm{~min}$. Mean intensity ranged from 1.2 to $68.2 \mathrm{~mm} \mathrm{~h}^{-1}$. Instantaneous maximum intensity, 
Table I. Characteristics of the rain events

\begin{tabular}{|c|c|c|c|c|c|c|}
\hline \multirow[t]{2}{*}{ Date } & \multicolumn{6}{|c|}{ Rain event } \\
\hline & $\begin{array}{l}\text { Starting } \\
\text { time }\end{array}$ & Cessationtime & $\begin{array}{l}\text { Duration } \\
\text { (min) }\end{array}$ & $\begin{array}{l}\text { Mean intensity } \\
\quad\left(\mathrm{mm} \mathrm{h}^{-1}\right)\end{array}$ & $\begin{array}{l}\text { Instantaneous }{ }^{\mathrm{a}} \text { maximum } \\
\text { intensity }\left(\mathrm{mm} \mathrm{h}^{-1}\right)\end{array}$ & $\begin{array}{l}\text { Total } \\
(\mathrm{mm})\end{array}$ \\
\hline 21 Jun 2001 & $04: 14$ & $06: 06$ & 112 & $5 \cdot 9$ & $64 \cdot 3$ & $11 \cdot 0$ \\
\hline 27 Jun 2001 & $12: 42$ & $12: 50$ & 8 & $49 \cdot 5$ & $78 \cdot 3$ & $6 \cdot 0$ \\
\hline 30 Jun-2001 & $04: 32$ & $07: 35$ & 183 & $5 \cdot 1$ & $81 \cdot 8$ & $15 \cdot 5$ \\
\hline 16 Jul 2001 & $04: 12$ & $10: 53$ & 401 & $2 \cdot 5$ & $20 \cdot 7$ & $16 \cdot 5$ \\
\hline 22 Jul 2001 & $03: 19$ & $06: 00$ & 161 & $6 \cdot 5$ & $26 \cdot 5$ & $17 \cdot 5$ \\
\hline 26 Jul 2001 & $00: 45$ & $07: 15$ & 390 & $2 \cdot 8$ & $30 \cdot 5$ & $18 \cdot 5$ \\
\hline 28 Jul 2001 & $12: 15$ & $12: 30$ & 15 & $8 \cdot 3$ & $12 \cdot 2$ & $2 \cdot 0$ \\
\hline 2 Aug 2001 & $12: 52$ & $12: 53$ & 1 & $58 \cdot 1$ & $46 \cdot 2$ & $1 \cdot 5$ \\
\hline 3-4 Aug 2001 & $23: 29$ & $08: 30$ & 541 & $3 \cdot 6$ & 54.5 & $32 \cdot 5$ \\
\hline 30 Aug 2001 & $15: 07$ & $15: 41$ & 34 & $10 \cdot 3$ & $41 \cdot 9$ & $6 \cdot 0$ \\
\hline 9 Sep 2001 & $03: 23$ & $09: 29$ & 366 & $2 \cdot 3$ & $42 \cdot 9$ & $14 \cdot 0$ \\
\hline 17 Sep 2001 & $12: 52$ & $13: 55$ & 63 & $68 \cdot 2$ & $300 \cdot 0$ & $71 \cdot 0$ \\
\hline 3 Oct 2001 & $08: 28$ & $09: 43$ & 75 & $1 \cdot 2$ & $1 \cdot 1$ & $1 \cdot 5$ \\
\hline 9 Jan 2002 & $13: 52$ & $13: 57$ & 5 & $18 \cdot 2$ & $12 \cdot 8$ & $1 \cdot 5$ \\
\hline 17 Jan 2002 & $07: 03$ & $10: 17$ & 194 & 4.5 & $66 \cdot 7$ & $14 \cdot 5$ \\
\hline 13 Feb 2002 & $14: 59$ & $15: 05$ & 6 & $46 \cdot 8$ & $81 \cdot 8$ & $5 \cdot 0$ \\
\hline 15 Feb 2002 & $06: 14$ & $07: 27$ & 73 & $3 \cdot 3$ & $56 \cdot 3$ & $4 \cdot 0$ \\
\hline 20 Feb 2002 & $04: 31$ & $07: 03$ & 152 & $1 \cdot 2$ & 1.9 & $3 \cdot 0$ \\
\hline 22 Feb 2002 & $05: 14$ & $07: 54$ & 160 & 1.5 & $10 \cdot 1$ & $4 \cdot 0$ \\
\hline 24 Feb 2002 & $13: 41$ & $14: 49$ & 68 & $11 \cdot 0$ & $81 \cdot 8$ & $12 \cdot 5$ \\
\hline 26 Feb 2002 & $12: 07$ & $14: 11$ & 124 & $7 \cdot 0$ & $90 \cdot 0$ & $14 \cdot 5$ \\
\hline 27 Feb 2002 & $12: 53$ & $13: 01$ & 8 & $10 \cdot 5$ & $11 \cdot 4$ & $1 \cdot 5$ \\
\hline
\end{tabular}

${ }^{a}$ These values were calculated using the minimum time interval it takes to refill the $0.5 \mathrm{~mm}$ tipping bucket for each rainfall event.

which was calculated using the minimum time to refill the $0.5 \mathrm{~mm}$ tipping bucket at each rain event, ranged from 1.1 to $225.0 \mathrm{~mm} \mathrm{~h}^{-1}$. Total rainfall at each rain event was within $71.0 \mathrm{~mm}$.

Figure 4 shows the relationship between the time that rainfall ceases and ECDT. When rainfall ceased before noon, ECDTs were distributed widely: the midpoint between ECDT_ $S$ and ECDT_ $L$ at each event ranged from 126 to $534 \mathrm{~min}$, with a mean midpoint of $240 \pm 116(n=12)$. The slanted, broken line in Figure 4 indicates the time remaining until noon at each rainfall cessation. A number of ECDTs are plotted around this line, indicating that sap flow velocities remained low until around noon if the rainfall event ceased before noon. However, ECDTs were distributed more narrowly when rainfall ceased after noon: the midpoint between ECDT_ $S$ and ECDT $L$ at each event ranged from 39 to 183 min, with a mean midpoint of $93 \pm 41$ $\min (n=10)$. The distributions of ECDT were quite different before and after noon. In this paper we grouped rain events into two types: Type 1 represents rain events that ceased before noon and Type 2 represents rain events that ceased after noon.

\section{Factors determining ECDT}

Figure 5 shows typical diurnal courses of sap flow velocity for Type 1 and Type 2 rainfall events, as well as $\mathrm{Rn}$ and VPD with the average diurnal course for bright days. Total rainfall was recorded as $32.5 \mathrm{~mm}$ during the 541 min between $23: 29$ on 3 August and $08: 30$ on 4 August 2001 (Type 1). After the rainfall, Rn and VPD increased slowly compared with the average diurnal course for bright days. During the same period, the sap flow velocity increased as slowly as Rn and VPD, and the ECDT was $200 \leq$ ECDT $\leq 360$ min. On 17 September (Type 2), total rainfall was $71 \mathrm{~mm}$ during the $63 \mathrm{~min}$ between $12: 52$ and 13:55. Sap flow velocity increased as rapidly as Rn and VPD after the rainfall. In this case, the ECDT was $65 \leq$ ECDT $\leq 145$ min. 




Figure 4. ECDT in relation to the time rainfall ceased. ECDT for each rain event is indicated as the range between ECDT_ $S$ and ECDT_ $L$ for each rain event. The slanting broken line indicates the time remaining until noon after each cessation time

CDT generally varies according to evaporation rates after rainfall under the condition that the canopy is fully wet, since evaporation rate is the important factor controlling wet canopy evaporation (e.g. Rutter et al., 1975; Gash, 1979; Suzuki et al., 1979).

Evaporation rates increase with increasing Rn and VPD according to the Penman (1948) equation. To examine the relationships between ECDT, Rn, and VPD, the following terms are defined: $\overline{\mathrm{Rn}}$ is the mean Rn in the period from $A$ to the midpoint between $S$ and $L$; VPD is the mean VPD in the period from $A$ to the midpoint between $S$ and $L$. Figure 6 shows the relationships between ECDT, $\overline{\mathrm{Rn}}$ and $\overline{\mathrm{VPD}}$, as well as the relationship between $\overline{\mathrm{Rn}}$ and $\overline{\mathrm{VPD}}$. Although ECDT mainly decreases with increasing $\overline{\mathrm{Rn}}$, Type 2 events had shorter ECDTs than Type 1 events, and the relationship between ECDT and $\overline{\mathrm{Rn}}$ was clearer for the Type 2 rainfall events than the Type 1 events(Figure 6a). We found a positive linear relationship between $\overline{\mathrm{Rn}}$ and $\overline{\mathrm{VPD}}$ for both rainfall types (Figure 6c), but several Type 2 events with $\overline{\mathrm{Rn}}<250 \mathrm{~W} \mathrm{~m}^{-2}$ had VPD values greater than those of Type 1 events, which may cause the ECDTs after Type 2 rainfall events with $\overline{\mathrm{Rn}}<250 \mathrm{~W} \mathrm{~m}{ }^{-2}$ to be shorter than those of Type 1 (Figure 6a). ECDT also decreases with increasing VPD (Figure 6b). We found the same tendency in the relationships between ECDT $S$ and the mean Rn and the mean VPD in the period from $A$ to $S$, and the relationships between ECDT $L$ and the mean $\mathrm{Rn}_{-}$and the mean VPD in the period from $A$ to $L$.

ECDTs of both Type 1 and Type 2 events decreased with increasing Rn and VPD. These results suggest that ECDT is determined mainly by the evaporation rate after rainfall. This relationship between ECDT and the evaporation rate corresponds with the general relationship suggested by previous studies (Rutter et al., 1975; Gash, 1979; Suzuki et al., 1979) and suggests that ECDT can be used as part of the data validating a wet canopy evaporation model.

\section{Practical limitations of sap flow measurements for detecting canopy wetness}

Using sap flow measurements for detecting canopy wetness has an advantage over the use of wetness sensors placed at different heights within a canopy, because sap flow velocities that can be measured readily at a single sensor provide information about integrated leaf wetness conditions throughout the canopy of an 

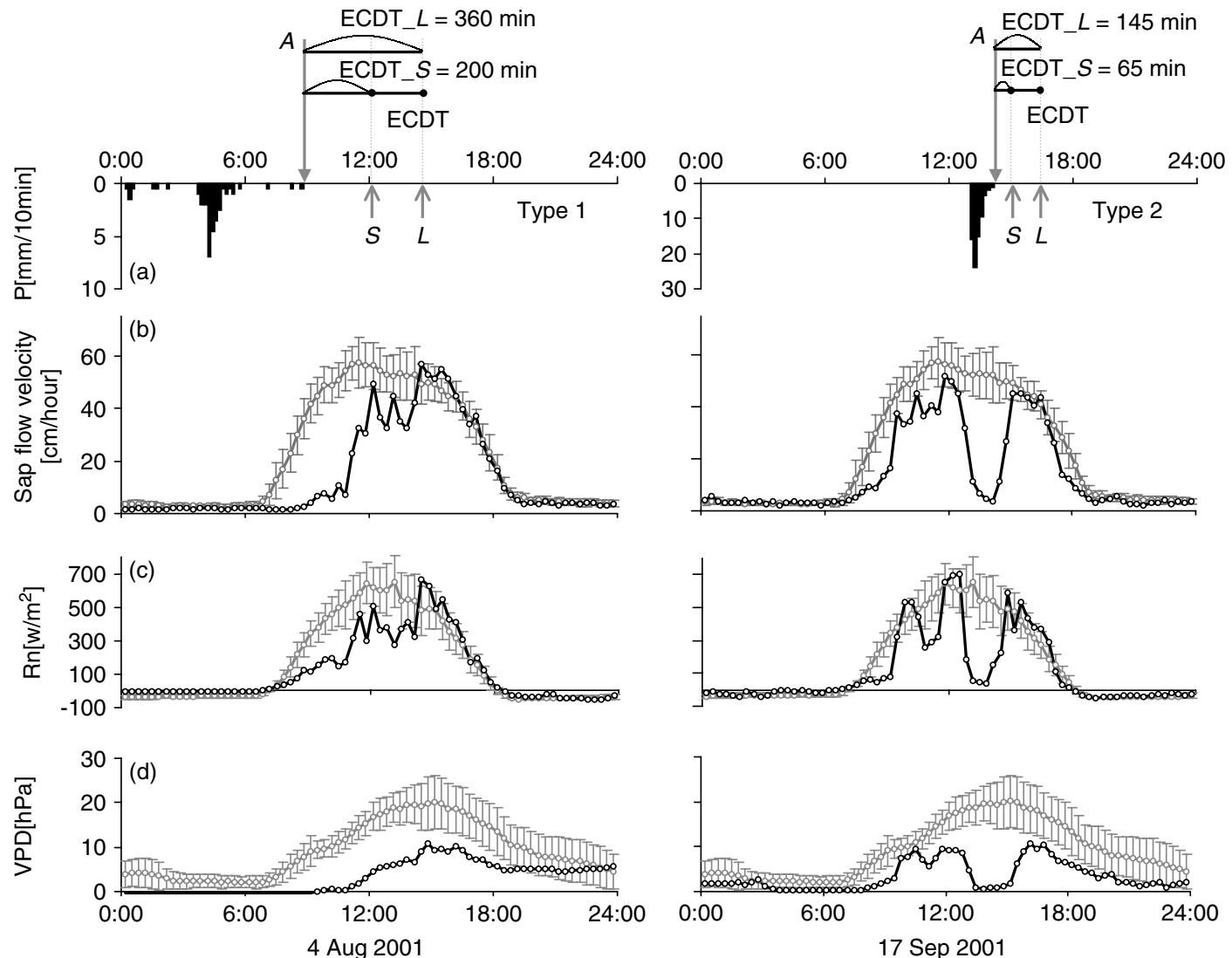

Figure 5. Typical diurnal courses for Type 1 and Type 2: (a) rainfall $P$; (b) sap flow velocity; (c) Rn; (d) VPD. Values averaged over 20 bright days are also shown with the standard deviations indicated by vertical bars. ECDT_ $S$, ECDT_ $L, A, S, L$ are defined in the text
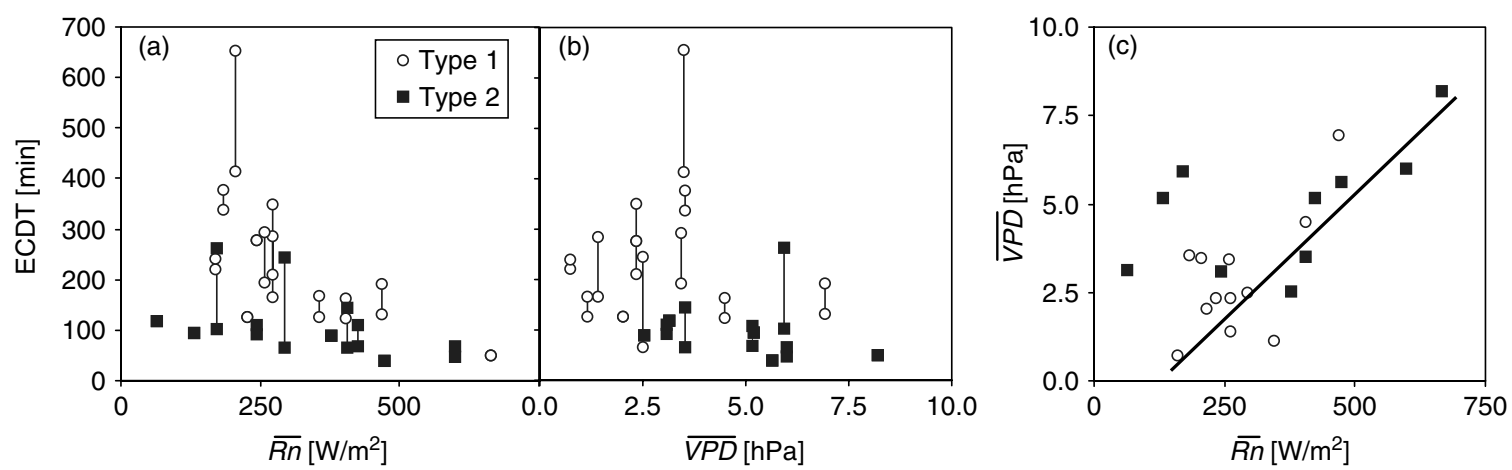

Figure 6. ECDT in relation to (a) $\overline{\mathrm{Rn}}$, (b) $\overline{\mathrm{VPD}}$, and (c) the relationship between $\overline{\mathrm{Rn}}$ and $\overline{\mathrm{VPD}}$ for Type 1 (O) and Type 2 ( $\mathbf{\square})$. The line in (c) was drawn by hand to show the tendency of the relationship; it is not a regression line

entire tree. However, there are two major practical limitations to be considered: one is an issue concerning rainfall characteristics, the other is the time lag between transpiration and sap flow through a stem.

Successfully detecting canopy wetness using sap flow measurements depends on the rainfall characteristics of the forest under study. In our study, total rainfall in the data set period was distributed over 94 rain events, 


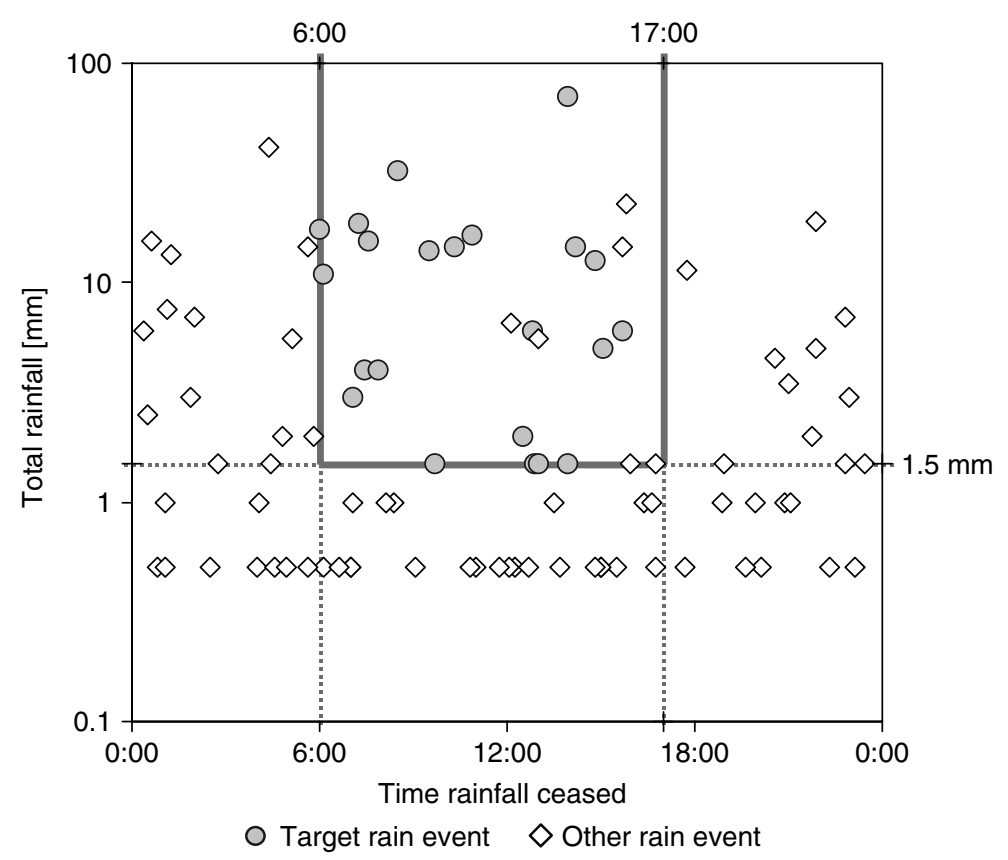

Figure 7. Total rainfall at each rain event in relation to the time of rainfall cessation in 94 rain events. The 94 rain events were the rain events that were separated by a no-rain period of $2 \mathrm{~h}$. The $Y$-axis is represented by a logarithmic scale. The closed grey circle indicates a target rain event; the open diamond indicates a rain event that was not selected as a target rain event in this study

when the rain events were separated by no rain periods of $2 \mathrm{~h}$. Figure 7 shows the relationship between the time that rainfall ceased and the total rainfall in 94 rain events. Forty-three rain events $(46 \%$ of 94 rain events) ceased during the night from 17:00 to 06:00; these rain events were omitted. There were 23 rain events (24\% of 94 rain events) among 51 rain events in which rainfall ceased in the daytime from 6:00 to 17: 00 but did not exceed the threshold of $1.5 \mathrm{~mm}$. Thus, these 23 rain events were omitted. Among 28 rain events in which the total rainfall exceeded the threshold of $1.5 \mathrm{~mm}$, we could not calculate ECDT for six of them (7\% of 94 rain events), as the sap flow velocities after rainfall remained low until sunset. Consequently, the residual 22 rain events ( $23 \%$ of 94 rain events) were selected as target rain events. The specific rainfall characteristics at this site made it possible to record a sufficient number of rain events.

Figure 8 shows the diurnal cycle and seasonal changes in rainfall (adapted from Kuraji et al. (2001)). Rainfall at this site has a distinct diurnal cycle, with two peaks: one in the middle of the night from 23:00 to $02: 00$ and the other in the afternoon from 13:00 to 15:00 (Figure 8a). Most rainfall events can be divided into two types: midnight rainfall around the midnight peak and afternoon rainfall around the afternoon peak. It seems that midnight rainfall tends to cease in the morning at the latest and rarely occurs during the period between $08: 00$ and 12:00 (Figure 8c). In the afternoon, the rainfall rarely occurs between 15:00 and 18:00 (Figure 8c). In this study, regularly occurring periods of no rain in a $24 \mathrm{~h}$ day were helpful for estimating CDT using sap flow velocities. We can surmise that detecting canopy wetness by measuring sap flow velocity will also work well in the Amazonian forest (e.g. Lloyd, 1988) and the Malay Peninsula (Noguchi et al., 2003), where short rain events tend to occur in the daytime. On the other hand, it would be difficult to use this technique in eastern Puerto Rico (Schellekens et al., 2000), where rainfall occurrence is higher at night-time than during daylight hours.

This method may also be limited by a possible time lag between transpiration and sap flow that may affect the availability of ECDT in some cases. It has been reported that the change of sap flow in a basal stem trailed canopy transpiration (e.g. Phillips et al., 1997, 1999; Goldstein et al., 1998). This time lag was found 


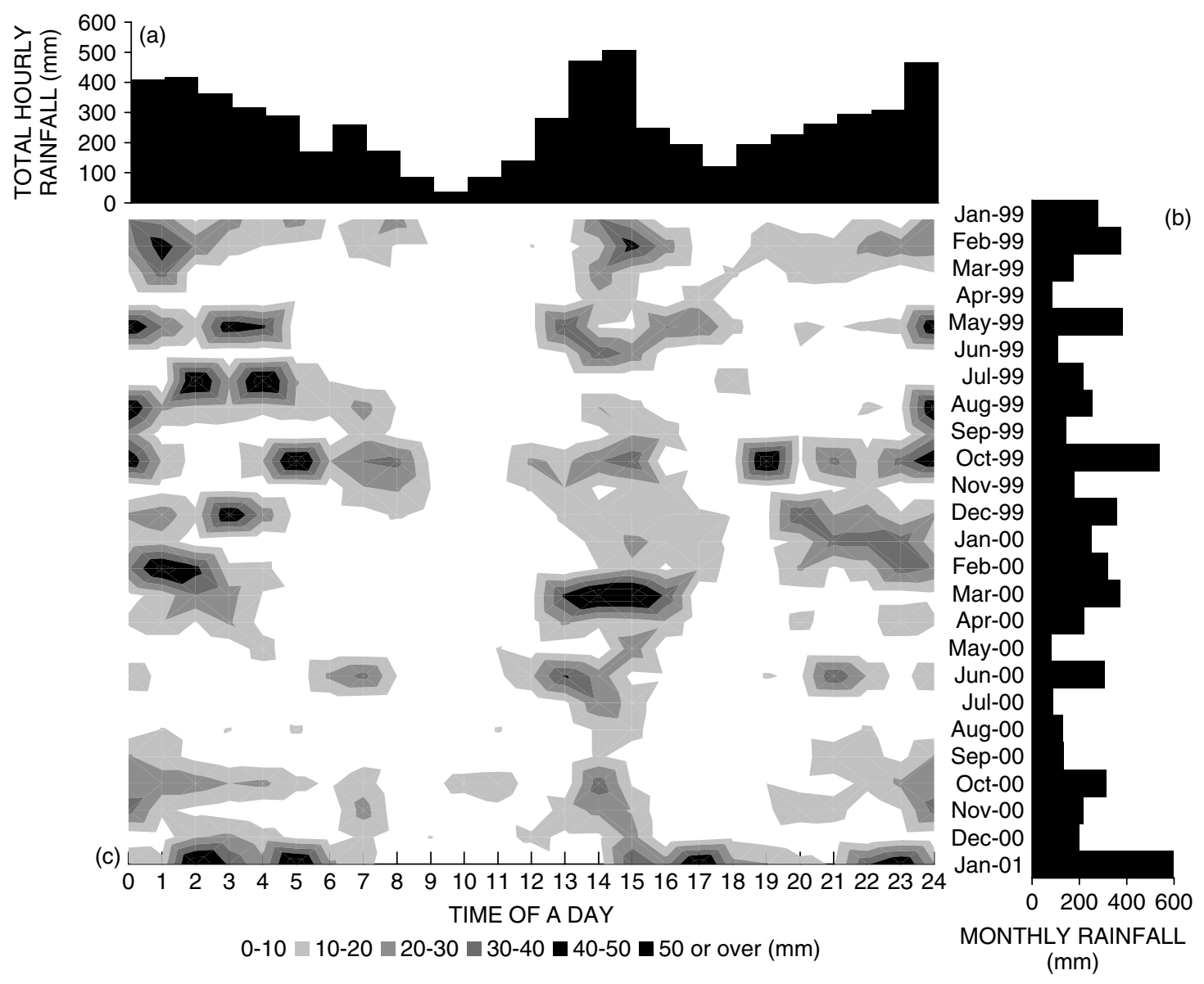

Figure 8. Rainfall at each time of day for each month. Data were adapted from Kuraji et al. (2001): (a) diurnal cycle of rainfall; (b) seasonal change of rainfall; (c) diurnal cycle of rainfall in each month

to be caused by internal water storage and hydraulic resistance in a tree (Landsberg et al., 1976; Kumagai, 2001).

However, at this site, a remarkable time lag between crown and basal sap flow was not observed when sap flow velocities in a branch at $50 \mathrm{~m}$ above the ground and at the stem above the buttresses were measured in another dipterocarp emergent tree ( $\mathrm{T}$. Kume, personal communication). This suggests that very similar results would be obtained regardless of sensor positions, and that the sensor could be installed at a more accessible point. On the contrary, when time lags were evidently observed (e.g. Phillips et al., 1997, 1999; Goldstein et al., 1998), the time lag would have added to the ECDT. Furthermore, it has been reported that the time lag became obvious only in the night and that the nocturnal sap flow occurred to refill internal water storage in a tree (e.g. Kenworthy, 1969; Caspari et al., 1993). This also makes it difficult to estimate CDT using sap flow velocities. However, such a nocturnal sap flow became obvious under severely dry conditions (Caspari et al., 1993). Thus, nocturnal sap flow rate might be low after a rainfall, to the extent that sap flow cannot be measured correctly by the heat-pulse method, and a limitation of this method is insensitivity at low sap flow rates (Becker, 1998).

This study reports the distributions and the determining factors of ECDT in the upper canopy using measurements in a single branch in a lowland tropical forest. When the time lag is negligible or corrected, 
the canopy drying process within a forest canopy in a tropical rain forest will also be examined using sap flow velocities measured at an accessible level without a special platform.

\section{CONCLUSIONS}

CDT after rainfall is one of the key aspects to understanding evapotranspiration processes in a lowland tropical rain forest, because of this forest's specific rainfall characteristics. In this study, ECDT has been defined as a range from ECDT_ $S$ (the shorter estimation) to ECDT_ $L$ (the longer estimation). ECDT_ $S$ and ECDT_ $L$ have been defined as two periods each beginning at the time rainfall ceased and each ending at a specific time derived from the difference between typical diurnal courses of sap flow velocities on bright days versus the measured sap flow on a rainy day. This study indicated the ECDT for each rain event and examined the factors determining ECDT in an emergent tree in a lowland mixed-dipterocarp forest.

ECDT could be derived for 22 rain events out of 94 rain events recorded at the study site that could be distinctly divided into two types. When rainfall ended before noon (Type 1), ECDTs were distributed more widely and with greater values than when rainfall ceased after noon (Type 2). The ECDTs of both Type 1 and Type 2 events decreased with increasing Rn and VPD after rainfall. These results show that ECDT is determined mainly by evaporation rates after rainfall, suggesting that ECDT can be used as part of the data for validating a wet canopy evaporation model.

Rainfall at this site has two distinct peaks in the diurnal variation pattern, one near midnight and the other in the afternoon, with periods when rainfall rarely occurs being observed in the morning and the afternoon. This diurnal variation pattern makes the estimation of CDT using sap flow velocities work well. When time lags between transpirations and sap flow in a basal stem can be considered, more measurements on individual trees encompassing various heights will allow a better understanding of canopy drying processes within a forest canopy.

\section{ACKNOWLEDGEMENTS}

This work was supported by the CREST program of the JST (Japan Science and Technology Corporation). We would like to express our appreciation to the Forest Research Center of the Sarawak Forestry Corporation and the Forestry Department Sarawak, for their cooperation with our work in Lambir. Some of the meteorological equipment was installed by Dr Tomo'omi Kumagai of the University of Kyushu, Dr Katsunori Tanaka of the Frontier Research System for Global Change, and Ms Yuri Tanaka. Fruitful discussions with Dr Nobuaki Tanaka, Dr Hikaru Komatsu, Mr Norifumi Hotta and Mr Odair Jóse Manfroi, from the University of Tokyo, and two anonymous reviewers' comments are also greatly appreciated.

\section{REFERENCES}

Asdak C, Jarvis PG, van Gardingen P, Frase A. 1998. Rainfall interception loss in unlogged forest area of central Kalimantan, Indonesia. Journal of Hydrology 206: 237-244. DOI: 10·1016/S0022-1694(98)00108-5.

Becker P. 1996. Sap flow in Bornean heath and dipterocarp forest trees during wet and dry periods. Tree Physiology 16: $295-299$.

Becker P. 1998. Limitation of a compensation heat pulse velocity system at low sap flow: implications for measurements at night and in shaded trees. Tree Physiology 18: 177-184.

Bigelow S. 2001. Evapotranspiration modelled from stands of three broad-leaved tropical trees in Costa Rica. Hydrological Processes 15: 2779-2796. DOI: 10·1002/hyp.268.

Bosveld FC, Bouten W. 2003. Evaluation a model of evaporation and transpiration with observations in a partially wet Douglas-fir forest. Boundary-Layer Meteorology 108: 365-396.

Bouten W, Schaap MG, Aerts J, Vermetten AWM. 1996. Monitoring and modeling canopy water storage amounts in support of atmospheric deposition studies. Journal of Hydrology 181: 305-321. DOI: 10·1016/0022-1694(95)02907-9.

Calder IR, Wright IR. 1986. Gamma ray attenuation studies of interception from sitka spruce: some evidence for additional transport mechanism. Water Resources Research 22: 409-417. 
Caspari HW, Green SR, Edwards WRN. 1993. Transpiration of well-watered and water-stressed Asian pear trees as determined by lysimetry, heat-pulse, and estimated by a Penman-Monteith model. Agricultural and Forest Meteorology 67: 13-27. DOI:10·1016/01681923(93)90047-L.

Cienciala E, Kucera J, Malmer A. 2000. Tree sap flow and stand transpiration of two Acasia mangium plantations in Sabah, Borneo. Journal of Hydrology 236: 109-120. DOI: 10·1016/S0022-1694(00)00291-2.

Closs RH. 1958. The heat pulse method for measuring rate of sap flow in a plant stem. New Zealand Journal of Science 1: 281-288.

Condit R, Ashton PS, Baker P, Bunyavejchewin S, Gunatilleke S, Gunatilleke N, Hubbell SP, Foster RB, Itoh A, LaFrankie JV, Lee HS, Losos E, Manokaran N, Sukumar R, Yamakura T. 2000. Spatial patterns in the distribution of tropical tree species. Science 288: $1414-1418$.

Dykes AP. 1997. Rainfall interception from a lowland tropical rainforest in Brunei. Journal of Hydrology 200: 260-279. DOI: 10·1016/s00221694(97)00023-1.

Gash JHC. 1979. An analytical model of rainfall interception by forests. Quarterly Journal of the Royal Meteorological Society 105: $43-55$.

Giesler LJ, Horst GL, Yuen GY. 1996. A site-specific sensor for measuring leaf wetness duration within turfgrass canopies. Agricultural and Forest Meteorology 81: 145-156. DOI: 10·1016/0168-1923(95)02302-X.

Goldstein G, Andrade JL, Meinzer FC, Holbrook NM, Cavelier J, Jackson P, Celis A. 1998. Stem water storage and diurnal patterns of water use in tropical forest canopy trees. Plant, Cell and Environment 21: 397-406.

Granier A, Huc R, Barigah ST. 1996. Transpiration of natural rain forest and its dependence on climatic factors. Agricultural and Forest Meteorology 78: 19-29. DOI: 10·1016/0168-1923(95)02252-X.

Hiromi T, Ninomiya I, Koike T, Ogino K. 1999. Reguration of transpiration by patchy stomatal opening in canopy tree species of Dipterocarpaceae in tropical rainforest, Sarawak, Malaysia. Japanese Journal of Ecology 49: 83-90 (in Japanese with English summary).

Hogg EH, Hurdle PA. 1997. Sap flow in trembling aspen: implications for stomatal responses to vapor pressure deficit. Tree Physiology 17: $501-509$.

Houghton RA, Hackler JL. 1999. Emission of carbon from forestry and land-use change in tropical Asia. Global Change Biology 5: $481-492$. DOI: $10 \cdot 1046 / j .1365-2486 \cdot 1999 \cdot 00244 . x$.

Ishibashi M, Terashima I. 1995. Effects of continuous leaf wetness on photosynthesis: adverse aspects of rainfall. Plant, Cell and Environment 18: $431-438$

Itoh A, Yamakura T, Ogino K, Lee HS, Ashton PS. 1997. Spatial distribution patterns of two predominant emergent trees in a tropical rainforest in Sarawak, Malaysia. Plant Ecology 132: 121-136. DOI: 10·1023/A:1009779424279.

Jackson IJ. 1975. Relationships between rainfall parameters and interception by tropical forest. Journal of Hydrology 24: 215-238.

Jetten VG. 1996. Interception of tropical rain forest: performance of a canopy water balance model. Hydrological Processes 10: 671-685.

Kanae S, Oki T, Mushiake K. 2001. Impact of deforestation on regional precipitation over the Indochina Peninsula. Journal of Hydrometeorology 2: $51-70$.

Kenworthy JB. 1969. Water balance in the tropical rain forest: a preliminary study in the Ulu Gombak Forest Reserve. Malayan Nature Journal 22: 129-135.

Kimura K, Tanakamaru S. 1982. Studies on plant response to rainfall. (III) Stomatal response to rainfall. Journal of Agricultural Meteorology (Tokyo) 38: 239-243 (in Japanese with English summary).

Kira T. 1978. Community architecture and organic matter dynamics in tropical lowland rain forests of southeast Asia with special reference to Pasoh Forest, West Malaysia. In Tropical Trees as Living Systems, Tomlinson TB, Zinmerman MH (eds). Cambrige University Press: Cambridge; 561-590.

Kominami Y, Suzuki M. 1993. Comparison of transpiration rate measured by heat pulse method and water uptake rate in single trees of Chamaecyparis obtusa and Pinus densiflora. Exchange Processes at the Land Surface for a Range of Space and Time Scales, Bolle H-J, Feddes RA, Kalma JD (eds). IAHS Publication No. 212. IAHS Press: Wallingford; 27-34.

Kumagai T. 2001. Modeling water transportation and storage in sapwood-model development and validation. Agricultural and Forest Meteorology 109: 105-115. DOI: 10.1016/S0168-1923(01)00261-1.

Kumagai T, Kuraji K, Noguchi H, Tanaka Y, Tanaka K, Suzuki M. 2001. Vertical profiles of environmental factors within tropical rainforest, Lambir Hills National Park, Sarawak, Malaysia. Journal of Forest Research 6: 257-264.

Kuraji K. 1996. Hydrological characteristics of moist tropical forest. Bulletin of the Tokyo University Forests 95: $93-208$ (in Japanese with English summary).

Kuraji K, Tanaka Y, Kumagai T, Suzuki M. 2001. Long-term monitoring of the physical environment in and above the canopy and underground in Lambir Hills National Park. In Proceedings of the International Symposium, Canopy Processes and Ecological Roles of Tropical Rain Forest, Miri, Sarawak, Malaysia; 72-77.

Kuwada T, Kotake T, Takeuchi S, Maximov TC, Yoshikawa K. 2002. Relationships among water dynamics, soil moisture and vapor pressure deficit in a Larix gmelinii stand, eastern boreal Siberia. Journal of Japanese Forest Society 84: 246-254. (in Japanese with English summary).

Lagergren F, Lindroth A. 2002. Transpiration response to soil moisture in pine and spruce trees in Sweden. Agricultural and Forest Meteorology 112: 67-85. DOI: 10·1016/S0168-1923(02)00060-6.

Landsberg JJ, Blanchard TW, Warrit B. 1976. Studies on the movement of water through apple trees. Journal of Experimental Botany 27: $579-596$.

Lloyd CR, Gash JHC, Shuttleworth WJ. 1988. The measurement and modeling of rainfall interception by Amazonian rain forest. Agricultural and Forest Meteorology 43: 277-294. DOI: 10·1016/0168-1923(88)90055-X.

Lopushinsky W. 1986. Seasonal and diurnal trends of heat pulse velocity in Douglas-fir and ponderosa pine. Canadian Journal of Forest Research 16: 814-821.

Manfroi OJ, Kuraji K, Tanaka N, Suzuki M, Nakagawa M, Nakashizuka T, Chong L. 2004. The stemflow of trees in a Bornean lowland tropical forest. Hydrological Processes 18: 2455-2474.

Marshall DC. 1958. Measurement of sap flow in conifers by heat transport. Plant Physiology 33: 385-396. 
Martinez-Vilalta J, Mangiron M, Ogaya R, Sauret M, Serrano L, Penuelas J, Pinol J. 2003. Sap flow of three co-occurring Mediterranean woody species under varying atmospheric and soil water conditions. Tree Physiology 23: 747-758.

Meinzer FC, Goldstein G, Holbrook NM, Jackson P, Cavelier J. 1993. Stomatal and environmental control of transpiration in a lowland tropical forest tree. Plant, Cell and Environment 16: 429-436.

Miranda RAC, Davies TD, Cornell SE. 2000. A laboratory assessment of wetness sensors for leaf, fruit and trunk surfaces. Agricultural and Forest Meteorology 102: 263-274. DOI: 10·1016/S0168-1923(00)00127-1.

Monzi M. 1937. Beeinflussung der Spaltöffnungswerte durch Regenfall. Japanese Journal of Botany 9: 131-141 (in German).

O'Brien JJ, Oberbauer SF, Clark DB. 2004. Whole tree xylem sap flow responses to multiple environmental variables in a wet tropical forest. Plant, Cell and Environment 27: 551-567.

Noguchi S, Abdul Rahim N, Tani M. 2003. Rainfall characteristics of tropical rainforest at Pasoh Forest Reserve, Negeri Sembilan, Peninsular Malaysia. In Paso Ecology of a Lowland Rain Forest in Southeast Asia, Okuda T, Manokaran N, Matsumoto Y, Niiyama K, Thomas SC, Ashton PS (eds). Springer-Verlag: Tokyo; 51-58.

Penman HL. 1948. Natural evaporation from open water, bare soil and grass. Proceedings of the Royal Society of London, Series A 193: $120-145$.

Phillips N, Nagchaudhuri A, Oren R, Katul G. 1997. Time constant for water transport in loblolly pine trees estimated from time series of evaporative demand and stem sapflow. Trees 11: 412-419.

Phillips N, Oren R, Zimmermann R, Wright SJ. 1999. Temporal patterns of water flux in trees and lianas in a Panamanian moist forest. Trees 14: 116-123.

Rutter AJ, Morton AJ, Robins PC. 1975. A predictive model of rainfall interception in forests (II). Generalization of the model and comparison with observations in some coniferous and hardwood stands. Journal of Applied Ecology 12: 367-380.

Schellekens J, Bruijnzeel LA, Scatena FN, Bink NJ, Holwerda F. 2000. Evapotranspiration from a tropical rain forest, Luquillo Experimental Forest, eastern Puerto Rico. Water Resources Research 36: 2183-2196.

Suzuki M, Kato H, Tani M, Fukushima Y. 1979. Throughfall, stemflow and rainfall interception in the Kiryu Experimental Catchment (II). Rainfall interception. Journal of the Japan Forestry Society 61: 391-398 (in Japanese with English summary).

Swanson RH. 1994. Significant historical developments in thermal methods for measuring sap flow in trees. Agricultural and Forest Meteorology 72: 113-132.

Swanson RH, Whitfield DWA. 1981. A numerical analysis of heat pulse velocity theory and practice. Journal of Experimental Botany 32: $221-239$

Takanashi S, Kosugi Y, Tani M, Ohte N, Yano M, Tanaka H, Tanaka K. 2003. Evaporation from a Japanese cypress forest during and after rainfall. Journal of Japan Society of Hydrology \& Water Resources 16: 268-283 (in Japanese with English summary).

Tanaka K, Takizawa H, Tanaka N, Kosaka I, Yosifuji N, Tantasirin C, Piman S, Suzuki M, Tangtham N. 2003. Transpiration peak over a hill evergreen forest in northern Thailand in the late dry season: assessing the seasonal change in evapotranspiration using a multi-layer model. Journal of Geophysical Research-Atmospheres 108: 4533-4548. DOI: 10·1029/2002JD003028.

Watanabe T, Mizutani K. 1996. Model study on micrometeorological aspects of rainfall interception over an evergreen broad-leaved forest. Agricultural and Forest Meteorology 80: 195-214. DOI: 10·1016/0168-1923(95)02301-1.

Wei YQ, Bailey BJ, Stenning BC. 1995. A wetness sensor for detecting condensation on tomato plants in greenhouses. Journal of Agricultural Engineering Research 61: 197-204. DOI: 10·1006/jaer.1995·1047.

Wullschleger SD, Meinzer FC, Vertessy RA. 1998. A review of whole-plant water use studies in tree. Tree Physiology 18: 499-512.

Yamakura T, Kanzaki M, Itoh A, Ohkubo T, Ogino K, Chai EOK, Lee HS, Ashton PS. 1995. Forest architecture of Lambir rain forest revealed by a large-scale research plot. In Reports of New Program for Promotion of Basic Sciences: Studies of Global Environmental Changes with Special Reference to Asia and Pacific Regions, Ehime University, Japan, Vol. II-3; 2-20.

Yoshifuji N, Kume T, Tanaka N, Tantasirin C, Takizawa H, Suzuki M, Tangtham N. 2001. Comparison of seasonal trend in sap flow rate between deciduous and evergreen trees in northern Thailand. In Proceedings of the Fifth International Study Conference on GEWEX in Asia and GAME 2; 395-399. 